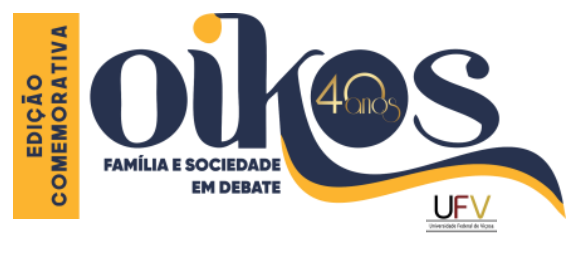

FARIAS, Rita de Cássia Pereira. 40 anos da Revista Oikos: Edição comemorativa. Oikos: Família e Sociedade em Debate, v. 32, n. 3, p. 1-5, 2021.

Doi: https://doi.org/10.31423/oikos.v32i3.13540

www.periodicos.ufv.br/oikos | ISSN: 2236-8493

revistaoikos@ufv.br

\title{
40 ANOS DA REVISTA OIKOS: EDIÇÃO COMEMORATIVA
}

Oikos é um termo grego que diz respeito ao lugar onde se vive. Envolve as relações que se desenvolvem em torno da produção e reprodução, do consumo, da economia, das transações comerciais, da posse e do cultivo da terra, dos bens materiais (imóveis, terras, animais), bem como as relações humanas.

Esse lugar onde se vive é marcado por relações de afeto, suporte emocional, cuidado, trocas de conhecimento, como também por exploração, dominação, violência, ódio e vingança.

No contexto da Grécia antiga, onde o termo Oikos surgiu, as relações eram frequentemente desiguais envolviam o domínio do homem pelo homem com a escravização das pessoas e exclusão de certos grupos do poder político (mulheres, escravos e as pessoas que não possuíam posses).

Conforme Engels (2019), o surgimento da propriedade privada levou à acumulação de bens o domínio do homem por outro homem ${ }^{1}$. Mais à frente, com o desenvolvimento do modo de produção, a descoberta de maquinários, a concentração dos trabalhadores nas fábricas, a extração da mais valia, a separação dos espaços de produção e reprodução ampliaram a dominação e a exploração. Consequentemente, aumentou-se a riqueza, de um lado, e a pobreza de outro. Diante das inseguranças, incertezas e dificuldades com a manutenção da própria vida, o ser humano, sendo relacional, busca suavizar a sua dor e suprir suas necessidades nas redes de relações que ele estabelece no ambiente em que vive.

As múltiplas relações humanas entre os iguais e os desiguais, marcadas por aproximações e evitações, confraternização e disputas são hierarquizadas por sexo, cor, raça, classe, geração, regionalismo e diversos outros marcadores que estruturam e complexificam as relações.

As Ciências Humanas e as Ciências Sociais tem buscado estudar a sociedade em suas múltiplas relações econômicas, políticas, ambientais, de solidariedade, de produção, de consumo e as mudanças ocorridas nos diferentes tempos e lugares, desvelando a complexidade do mundo social.

Esses estudos são divulgados em diferentes meios impressos e digitais, sendo a revista Oikos um deles. Esse periódico destina-se à publicação de produções científicas da área de

${ }^{1}$ ENGELS. Friedrich. Origem da Familia, da Propriedade Privada e do Estado. São Paulo: Boitempo. 2019. 
conhecimento das Ciências Humanas e Ciências Sociais Aplicadas. Os artigos são voltados para o estudo do ser humano como ser social, econômico e político, buscando refletir sobre as diversas realidades humanas e as consequências de viver em sociedade.

A Oikos: Revista Brasileira de Economia Doméstica foi criada durante a gestão da presidente da Associação Brasileira de Economia Doméstica (ABED), Professora Maria Lúcia Simonini e lançada em 1981, em Fortaleza, Ceará, durante o VI Congresso Brasileiro de Economia Doméstica, CBED.

A primeira edição impressa da revista foi publicada em 1981. Foi composta por uma Apresentação por Maria Lúcia Simonini e um Editorial por Tânia Araújo. A sessão Artigos, trouxe cinco publicações sendo uma sobre determinantes do emprego de mulheres com educação superior no Brasil e quatro sobre alimentação (dieta e suplementação alimentar; cocção de alimentos; valor nutricional e custo de dietas; consumo alimentar e variáveis socioeconômicas). A sessão Comunicações trouxe um texto de Maria Clarisse Ferreira Gomes e Regina Silva Oliveira Ferreira intitulado "Uma experiência em Educação Nutricional”. A sessão Instituições e Personalidade, trouxe 13 textos, sendo um tematizando "O pioneirismo da UFV no ensino, pesquisa e extensão no Brasil, um sobre a Faculdade de Ciências Domésticas em Pelotas", além de 11 textos sobre personalidades importantes para a Economia Doméstica: Eleonora Cebotarev, Elisa Clélia Miniono, Juan Enrique Diaz Bordenave, Lucia Maria Maffia, Manfredo Araújo de Oliveira, Maria Iracema de Sá, Maria Stella Levy, Olga de Sá, Sônia Coelho Alvarenga, Sônia da Silva e Tânia Araújo. A sessão Publicações da América Latina trouxe a indicação de 14 livros importantes para subsidiar o estudo da Economia Doméstica. A sessão Notícias trouxe 4 textos sobre A Economia Doméstica na empresa, O XIV Congresso Internacional da Federação Internacional de Economia Familiar (FIEF), o convenio da Economia Doméstica com a UNESCO e, a ação Extensionista da UFV via Programa Gilberto Melo.

Embora a revista estivesse vinculada à ABED até 2017, sua sede sempre se localizou no Departamento de Economia Doméstica da Universidade Federal de Viçosa - UFV, situada na cidade de Viçosa, Minas Gerais. No período em que foi publicada impressa (1981 a 2010), o serviço tipográfico foi realizado pela Imprensa da Universidade Federal de Viçosa. Conforme Mafra (2007, p. 232), a revista conseguiu "se auto-sustentar em quase todo o processo, utilizando da logística eficiente do DED/UFV para a sua divulgação e distribuição".

\footnotetext{
${ }^{2}$ MAFRA, Simone Caldas Tavares. Instituições e personalidades. In: Oikos: Revista Brasileira de Economia Doméstica. Vol 18, N. 1, 2007, pp. 229-234. Disponível em: https://drive.google.com/file/d/1Tun11qehWTlvUqk5q4q4DM54Q8d9zAX/view.
} 
No período de 1981 a 1984, a coordenação da Oikos esteve a cargo da Professora Maria Lúcia Simonini. Em 1982, a revista foi normatizada pelo CNPq, de acordo com a NB-52, Norma Brasileira para apresentação de publicações periódicas da Associação Brasileira de Normas Técnicas - ABNT, e recebeu o número internacional normatizado para publicações seriadas - ISSN 0101-5273.

Em 1984, foi aprovado o Regimento interno da Oikos e a professora Nerina Aires Coelho Marques foi designada como a primeira Diretora-Presidente da Oikos, atuando no período de 1984 a 1987. Em 1987 Maria Lucia Simonini retornou como Diretora-Presidente da Oikos, atuando até 1993 (GUIMARÃES, 1991, p. 72) ${ }^{3}$.

No período de 1994 a 1996 a Diretora-Presidente foi Sonia Coelho de Alvarenga. Entre 1997 a 2003 foi a professora Elza Maria Vidigal Guimarães e no período de 2004 a 2017 a professora Karla Maria Damiano Teixeira. Em 2011 a Oikos deixou de ser publicada na forma impressa e passou a ser divulgada na forma digital, o que ampliou a divulgação e reduziu os custos. Todo o sistema operacional da revista passou a ser gerenciado pelo Open Jornal Sistem - OJS.

Na edição de comemoração dos 30 anos da revista (v. 22, n.2 de 2011), Guimarães e Teixeira (2011, p. 1) mencionaram que:

\begin{abstract}
Durante seus 30 anos de circulação, vários foram os desafios enfrentados, podendo-se destacar, principalmente, a dificuldade financeira de se manter um periódico científico. A Revista passou, também, por muitas modificações, a fim de se adequar às exigências das agências de certificação e da Coordenação de Aperfeiçoamento de Pessoal de Nível Superior (Capes). Como exemplos, podemos citar a ampliação do seu corpo editorial, formado por membros de renome nacional e internacional; o novo leiaute de sua capa; o estabelecimento de regras mais rígidas para publicação; e, o mais recente, a disponibilização de seu conteúdo on-line. Apesar de todos os percalços, a Direção da Revista pode-se orgulhar do fato de ter sempre mantido a regularidade da publicação e, também, a qualidade dos seus artigos ${ }^{4}$.
\end{abstract}

A partir da Edição v. 28 n. 2 de 2017, a Oikos mudou a sua editora e sua configuração, com alteração de algumas terminologias, atendendo às normas editoriais mais recentes. $A$ Professora Rita de Cássia Pereira Farias assumiu como Editora-chefe do periódico e Ronan Leandro Zampier, como editor adjunto. O periódico passou a se intitular Oikos: Família e Sociedade em debate, ficando vinculado ao Programa de Pós-Graduação em Economia Doméstica, da Universidade Federal de Viçosa - UFV. O motivo da mudança de nomenclatura foi a intenção que a revista ampliasse o seu escopo e alcançasse autores de outras áreas de

\footnotetext{
${ }^{3}$ GUIMARÃES, Elza Maria Vidigal. Dez anos da Revista Brasileira de Economia Doméstica Oikos (1981-1991). In: Oikos: Revista Brasileira de Economia Doméstica, Vol 7, N.1, 1991, p.72-76. Disponível em: https://drive.google.com/file/d/12bvoarAAk1kgfOtdQska4nufUvR2tBZ0/view.

${ }^{4}$ GUIMARÃES, Elza Maria Vidigal; TEIXEIRA, Karla Maria Damiano. Editorial. In: Oikos: Revista Brasileira de Economia Doméstica, Viçosa, v. 22, n. 2, p. 1-2, 2011. Disponível em:

https://periodicos.ufv.br/oikos/article/view/3628/1905.
} 
formação e atuação que pesquisassem temas que tangenciam a relação entre família e sociedade.

A partir dessa mudança, a revista recebeu uma nova logomarca e novas capas, que se tornaram diferenciadas em cada edição, buscando retratar os temas das publicações, o que contou com a parceria com artistas como Graça Craidy e Erico Santos que autorizaram que suas obras fossem utilizadas nas capas da Oikos.

Além das publicações do tipo variata, a revista passou a construir dossiês temáticos (violência, covid, democracia, política social, consumo), recebeu doi (Digital Object Identifier) e foi inserida em diversos indexadores Internacionais (EZB - Electronic Journals Library, Google Scholar, PKP Index) e Nacionais (Periódicos de Minas, Sumários.org, Diadorim), sendo as estatísticas do periódico feitas pelo Google Scholar.

Em seus 40 anos, a revista sofreu diversas transformações e se consolidou. Como sua publicação é gratuita, a Oikos tem contado com o trabalho voluntário de muitas pessoas do Brasil e exterior que têm atuado na comissão científica, como pareceristas ad hoc e no comitê editorial. O trabalho dos editores adjuntos e Débora Pires Teixeira, Fabiano Eloy Atílio Batista, Glauber Soares Junior, Ítalo Augusto da Cunha Rodrigues e Gabriela Santos Gomes tem sido fundamental para o êxito da revista, atuando no Desk Review, editoração, elaboração da capa, fluxo do processo editorial, contato com os autores e processos de indexação.

As transformações que a Oikos passou nesses 40 anos indicam que muito foi feito e muitos desafios nos aguardam. Assim, nesta edição comemorativa, buscamos resgatar um pouco das memórias do percurso do periódico em seus 40 anos. Como parte desse processo, convidamos autores especialistas em determinados assuntos para fazerem uma análise sobre a produção da revista nas diferentes áreas. Elegemos 19 temas e convidamos autores com diversas formações e diferentes instituições para dissertar sobre as temáticas trabalhadas na revista nos 40 anos. Os artigos foram avaliados pelos próprios membros do comitê editorial da revista.

A análise das publicações dos 40 anos da Oikos sinalizou que os temas publicados nos primeiros números da revista eram de cunho mais técnico, voltados para a alimentação, habitação e vestuário, além de temas mais gerais da Economia Doméstica, como a economia familiar e o consumo. Posteriormente, a revista passou a ter mais abrangência e receber artigos das áreas das Ciências Humanas e Sociais, problematizando temas como políticas públicas, conjugalidade, ruptura de vínculos, maternidades, paternidades e cuidados; infância e adolescência; educação; gênero, trabalho feminino; trabalho, desemprego e aposentadoria; 
envelhecimento; cultura, identidade e saberes tradicionais; sociedades rurais e questão ambiental.

Foi um grande desafio para os autores, pelo volume de conteúdo que tiveram que trabalhar, mas foi muito positivo, pois as análises constituíram uma oportunidade para fazer uma reflexão crítica sobre a produção científica da Oikos em seus 40 anos, o que dará subsídios para alavancar o periódico em sua qualidade.

Rita de Cássia Pereira Farias

Editora Chefe da Oikos 